\title{
Flexural Strength and Hardness of Filler-Reinforced PMMA Targeted for Denture Base Application
}

\author{
Abdulaziz Alhotan ${ }^{1,2, *}$, Julian Yates ${ }^{1}$, Saleh Zidan ${ }^{1,3}$, Julfikar Haider ${ }^{1,4}\left(\mathbb{D}\right.$ and Nikolaos Silikas ${ }^{1}(\mathbb{D}$ \\ 1 Division of Dentistry, School of Medical Sciences, University of Manchester, Manchester M13 9PL, UK; \\ julian.yates@manchester.ac.uk (J.Y.); saleh_0072002@yahoo.co.uk (S.Z.); j.haider@mmu.ac.uk (J.H.); \\ nikolaos.silikas@manchester.ac.uk (N.S.) \\ 2 Dental Health Department, College of Applied Medical Sciences, King Saud University, \\ Riyadh 11454, Saudi Arabia \\ 3 Department of Dental Materials, Faculty of Dentistry, Sebha University, Sebha, Libya \\ 4 Department of Engineering, Manchester Metropolitan University, Manchester M1 5GD, UK \\ * Correspondence: abdulaziz.alhotan@postgrad.manchester.ac.uk; Tel.: +44-74-9232-3020
}

Citation: Alhotan, A.; Yates, J.;

Zidan, S.; Haider, J.; Silikas, N.

Flexural Strength and Hardness of Filler-Reinforced PMMA Targeted for Denture Base Application. Materials 2021, 14, 2659. https://doi.org/ $10.3390 /$ ma14102659

Academic Editor: Enrico Marchetti

Received: 23 April 2021

Accepted: 14 May 2021

Published: 19 May 2021

Publisher's Note: MDPI stays neutral with regard to jurisdictional claims in published maps and institutional affiliations.

Copyright: (c) 2021 by the authors. Licensee MDPI, Basel, Switzerland. This article is an open access article distributed under the terms and conditions of the Creative Commons Attribution (CC BY) license (https:// creativecommons.org/licenses/by/ $4.0 /)$.

\begin{abstract}
The aim of this work was to evaluate the flexural strength and surface hardness of heatcured Polymethyl methacrylate (PMMA) modified by the addition of $\mathrm{ZrO}_{2}$ nanoparticles, $\mathrm{TiO}_{2}$ nanoparticles, and E-glass fibre at different wt.\% concentrations. Specimens were fabricated and separated into four groups $(n=10)$ to measure both flexural strength and surface hardness. Group C was the control group. The specimens in the remaining three groups differed according to the ratio of filler to weight of PMMA resin (1.5\%, 3\%, 5\%, and 7\%). A three-point bending test was performed to determine the flexural strength, while the surface hardness was measured using the Vickers hardness. Scanning Electron Microscope (SEM) was employed to observe the fractured surface of the specimens. The flexural strength was significantly improved in the groups filled with $3 \mathrm{wt} . \% \mathrm{ZrO}_{2}$ and 5 and $7 \mathrm{wt}$.\% E-glass fibre in comparison to Group C. All the groups displayed a significantly higher surface hardness than Group C, with the exception of the $1.5 \% \mathrm{TiO}_{2}$ and $1.5 \% \mathrm{ZrO}_{2}$ groups. The optimal filler concentrations to enhance the flexural strength of PMMA resin were between $3-5 \% \mathrm{ZrO}_{2}, 1.5 \%$ $\mathrm{TiO}_{2}$, and 3-7\% E-glass fibre. Furthermore, for all composites, a filler concentration of $3 \mathrm{wt} . \%$ and above would significantly improve hardness.
\end{abstract}

Keywords: PMMA; $\mathrm{ZrO}_{2}$ nanoparticle; $\mathrm{TiO}_{2}$ nanoparticle; E-glass fibre; flexural strength; surface hardness

\section{Introduction}

Over the last few decades, research on dental biomaterials has significantly progressed, leading to notable improvements in the associated material properties and technologies and fundamentally transforming dental materials and restorative practices [1,2]. The major challenges that dental clinicians traditionally encounter in prosthetics and restorations pertain to the lack of biocompatibility of materials, the difficulty in achieving a natural appearance, and the inability to develop a material that can withstand exposure to the harsh oral environment $[1,3,4]$. PMMA has been a preferred choice in the production of denture bases since its introduction in 1930s [5,6]. While dental implants are increasingly being used as substitutes for natural teeth in both partially dentate and edentulous patients, PMMA remains the preferred choice for denture base construction [7]. The popularity of PMMA as a polymeric material among those currently available can be attributed to its functional properties [8,9]. PMMA has achieved its popularity due to several factors; including, easy manipulation and processing, fabrication with affordable equipment, aesthetically appealing, and biocompatibility [5,8,10-12]. However, as conventional PMMA denture bases are relatively brittle and weak, they have a propensity for mechanical failure, leading to a high risk of fracture $[5,11,13]$. Several clinical reports have concluded that complete 
maxillary dentures are at risk of midline fracture $[14,15]$. The majority of fractures result in the mouth during normal function [2]. This phenomenon can be attributed to the resin fatigue that results from deep scratches and stress intensification (mastication) $[11,14]$. The ever-changing dental requirements entail that denture materials are required to exhibit optimal mechanical performance $[5,16]$. Therefore, many investigators have attempted to modify PMMA denture bases in a bid to improve its mechanical performance $[5,11,13,17]$. Researchers have consistently focused on the use of filler materials as a means of modifying the properties of polymer composites and blends [10,12,18-21]. Numerous studies have investigated how various filler materials, such as metal-oxide nanoparticles $\left(\mathrm{ZrO}_{2}, \mathrm{TiO}_{2}\right.$, $\left.\mathrm{Al}_{2} \mathrm{O}_{3}\right)[5,21,22]$, polymeric fibre (nylon, carbon, aramid, polyethylene) [14,23], and glass fibre $[24,25]$ can improve the mechanical properties of PMMA denture base. However, while the findings of the existing studies have sometimes been promising, they have also frequently contradicted each other [26].

During the mid-1990s, researchers started investigating the use of novel fibres as potential fillers for enhancing the mechanical properties of PMMA denture bases [27]. These novel fibres were promising as a means of reinforcing denture bases due to their strength, biocompatibility and aesthetics $[10,23,28]$. However, the performance of polymer composites depends on many factors, such as the nature of the matrix bonding, resins used, manufacturing conditions, and fibre type, percentage, length, diameter, or orientation $[9,10,17]$. Amongst the fibres used in this application, E-glass fibre has a high level of chemical resistance, is comparatively cost effective, achieves an excellent aesthetic appearance and possesses good biological properties [29].

Recently, research has focused predominantly on nanoparticles, which are widely recognized as they are offering advantageous characteristics due to their size, shape, composition, and ability to enhance the existing properties of polymers [26,30]. The emerging science and technology in the field of nanofillers are promising for the fabrication of PMMA polymer composites [15,18-21]. A relatively new material called zirconium oxide $\left(\mathrm{ZrO}_{2}\right)$-also referred to as Zirconia — has grown in popularity [31,32] as it is a typical bioceramic and, therefore, exhibits a good bioactivity and biocompatibility. Zirconia also offers exceptional high flexural strength, fracture toughness and durability, in addition to good aesthetics [31-33]. Another nanomaterial that has attracted significant interest is titanium oxide $\left(\mathrm{TiO}_{2}\right)$. $\mathrm{TiO}_{2}$ offers suitable cost and mechanical properties, is chemically stable and is non-toxic [34].

The materials that are commonly used in dental prostheses are associated with a risk of deformation and related fracture [1,5]. Flexural loading simulates clinical situations in which dentures are exposed to complex of forces during service; for example, compressive, tensile, and shear forces [14,16]. Conventional PMMA is a brittle material; therefore, it often fails during complex loading [1]. Prior fracture, scratches, or small flaws on the surface of PMMA dentures can generate crack propagation, leading to the eventual failure of the denture $[4,16]$. Thus, softer materials tend to develop scratches during the acts of daily living, such as brushing, chewing, or cleaning. These scratches can ultimately lead to fracture $[35,36]$.

Many studies have concluded that the use of various fillers to reinforce heat-cured PMMA denture base resins can enhance their mechanical properties $[18,20,26,30]$. However, the existing literature does not include any systematic studies on the impact nano- $\mathrm{TiO}_{2}$, glass fibre, and nano- $\mathrm{ZrO}_{2}$ fillers have on the hardness and flexural strength of heat-cured PMMA denture base resins. Thus, further studies are required to pinpoint the optimal quantity of nano- $\mathrm{TiO}_{2}$, glass fibre, and nano- $\mathrm{ZrO} 2$ required to enhance the longevity and performance of PMMA denture base resins. The current study explores the influence of $\mathrm{ZrO}_{2}$ and $\mathrm{TiO}_{2}$ nanoparticles on the mechanical properties of PMMA acrylic resin, along with the popular glass fibre type "E". E-glass fibre is an accepted reinforcement for PMMA material $[6,29,37]$. The optimum concentration for dental reinforcements needs to be studied. Zirconium, titanium nanoparticles, and $\mathrm{E}$ glass fibres were systematically varied at concentrations of (1.5 wt. $\%, 3 \mathrm{wt} . \%, 5 \mathrm{wt} . \%$, and $7 \mathrm{wt} . \%)$. The research was underpinned 
by the null hypothesis that the inclusion of filler would not improve the surface hardness and flexural strength of the specimens.

\section{Material and Methods}

\subsection{Materials}

Table 1 presents the materials employed in this study. Conventional heat-polymerized acrylic resin consists of polymethylmethacrylate (PMMA) powder and liquid methyl methacrylate (MMA) monomer. In addition to the use of commercial $\mathrm{ZrO}_{2}, \mathrm{TiO}_{2}$ nanoparticles, and chopped E-glass fibre as filler materials, silane coupling agent (3-Trimethoxysilyl propyl methacrylate) and ethanol were employed to treat the surfaces of the filler before adding to PMMA.

Table 1. Materials used in the experiments.

\begin{tabular}{ccc}
\hline Material & Composition and Specifications & Manufacturer \\
\hline \multirow{2}{*}{ Lucitone-199TM } & Heat-polymerized acrylic resin & Dentsply International, York, \\
& Powder: PMMA; & PA, USA \\
Zirconium oxide & Zirconium(IV) oxide-yttria & Sigma Aldrich, \\
& stabilized, nanopowder, $<100 \mathrm{~nm}$ & Gillingham, UK \\
particle size & Sigma Aldrich, \\
Titanium oxide & Titanium(IV) oxide, anatase, & Gillingham, UK \\
& nanopowder, $<25$ nm particle size & Hebei Yuniu Fibreglass, \\
E-glass fibre & 3 mm in length, $15 \mu \mathrm{m}$ & Xingtai, China \\
& in diameter & Fisher Scientific, \\
Ethanol & Ethanol, absolute $\left(\mathrm{C}_{2} \mathrm{H}_{6} \mathrm{O}\right.$, EtOH) & Loughborough, UK \\
& 3-(Trimethoxysilyl)propyl & Sigma Aldrich, \\
Silane coupling agent & methacrylate, assay $98 \%$ & Gillingham, UK \\
\hline
\end{tabular}

\subsection{Method}

\subsubsection{Specimen Preparation}

In total, 130 rectangular specimens $(64 \mathrm{~mm}$ in length, $3.3 \pm 0.2 \mathrm{~mm}$ in thickness, and $10 \pm 0.2 \mathrm{~mm}$ in width) were fabricated. The samples were divided into four different groups: one control group (pure, heat-cured PMMA) and three experimental groups that differed according to the reinforcement materials incorporated into the PMMA: $\mathrm{ZrO}_{2}$, $\mathrm{TiO}_{2}$, and E-glass fibres. Each of the three reinforced PMMA groups ( $\mathrm{n}=10$ each group) were further sub-divided into four subgroups according to the concentration of filler used: $1.5 \%, 3 \%, 5 \%$, and $7 \%$ ) (Table 2). All the specimens were prepared according to the manufacturer's instructions and tested per ISO specifications [38,39], according to previous studies $[5,6,18,40]$.

Table 2. Specimen grouping and coding.

\begin{tabular}{|c|c|c|c|}
\hline Materials Group & $\begin{array}{c}\text { Group/Subgroup } \\
\text { Code }\end{array}$ & Material Description & $\begin{array}{l}\text { Number of } \\
\text { Specimens }\end{array}$ \\
\hline \multirow[t]{2}{*}{ Control } & C & PMMA acrylic resin & 10 \\
\hline & $\mathrm{Z1}$ & $\begin{array}{c}\text { PMMA acrylic resin + } \\
1.5 \text { wt. } \% \mathrm{ZrO}_{2}\end{array}$ & 10 \\
\hline \multirow[t]{3}{*}{$\mathrm{ZrO}_{2}$ nanoparticle } & $\mathrm{Z3}$ & $\begin{array}{c}\text { PMMA acrylic resin + } \\
3 \text { wt. } \% \mathrm{ZrO}_{2}\end{array}$ & 10 \\
\hline & $\mathrm{Z} 5$ & $\begin{array}{c}\text { PMMA acrylic resin + } \\
5 \text { wt. } \% \mathrm{ZrO}_{2}\end{array}$ & 10 \\
\hline & $\mathrm{Z7}$ & $\begin{array}{c}\text { PMMA acrylic resin + } \\
7 \text { wt. } \% \mathrm{ZrO}_{2}\end{array}$ & 10 \\
\hline
\end{tabular}


Table 2. Cont.

\begin{tabular}{|c|c|c|c|}
\hline Materials Group & $\begin{array}{c}\text { Group/Subgroup } \\
\text { Code }\end{array}$ & Material Description & $\begin{array}{l}\text { Number of } \\
\text { Specimens }\end{array}$ \\
\hline \multirow[b]{2}{*}{$\mathrm{TiO}_{2}$ nanoparticle } & $\mathrm{T} 1$ & $\begin{array}{c}\text { PMMA acrylic resin }+ \\
1.5 \text { wt. } \% \mathrm{TiO}_{2}\end{array}$ & 10 \\
\hline & T3 & $\begin{array}{c}\text { PMMA acrylic resin }+ \\
3 \text { wt. } \% \mathrm{TiO}_{2}\end{array}$ & 10 \\
\hline \multirow{6}{*}{ E-glass fibre } & T5 & $\begin{array}{c}\text { PMMA acrylic resin }+ \\
5 \text { wt. } \% \mathrm{TiO}_{2}\end{array}$ & 10 \\
\hline & $\mathrm{T} 7$ & $\begin{array}{c}\text { PMMA acrylic resin + } \\
7 \text { wt. } \% \mathrm{TiO}_{2}\end{array}$ & 10 \\
\hline & E1 & $\begin{array}{c}\text { PMMA acrylic resin + } \\
1.5 \text { wt. } \% \text { E-glass }\end{array}$ & 10 \\
\hline & E3 & $\begin{array}{c}\text { PMMA acrylic resin + } \\
3 \text { wt. } \% \text { E-glass }\end{array}$ & 10 \\
\hline & E5 & $\begin{array}{c}\text { PMMA acrylic resin + } \\
5 \text { wt. } \% \text { E-glass }\end{array}$ & 10 \\
\hline & E7 & $\begin{array}{c}\text { PMMA acrylic resin + } \\
7 \text { wt. } \% \text { E-glass }\end{array}$ & 10 \\
\hline
\end{tabular}

\subsubsection{Selecting Appropriate Filler/Saline Percentages}

Pilot studies determined that the percentages of the silanized fillers used should be $1.5 \mathrm{wt} . \%, 3 \mathrm{wt} . \%, 5 \mathrm{wt} . \%$, and $7 \mathrm{wt} . \%$. Table 3 illustrates the composition of all the specimen routes employed by this study. A ratio of heat-cured acrylic resin powder and monomer $(\mathrm{P} / \mathrm{L})$ ratio of $21 \mathrm{~g}: 10 \mathrm{~mL}$ was employed in accordance with the recommendations of the manufacturer; scaled appropriately, this meant that a proportion of $12 \mathrm{~g}$ to $5.7 \mathrm{~mL}$ for the mould was employed.

Table 3. Quantities of acrylic resin powder, monomer, and filler used in each group.

\begin{tabular}{cccc}
\hline Filler Concentration & $\begin{array}{c}\text { Filler in Each Mould } \\
(\mathbf{g})\end{array}$ & $\begin{array}{c}\text { PMMA Powder } \\
(\mathbf{g})\end{array}$ & $\begin{array}{c}\text { MMA Monomer } \\
(\mathbf{m L})\end{array}$ \\
\hline $0 \%($ Control) & 0.0 & 12.00 & 5.70 \\
$1.5 \%$ & 0.18 & 11.82 & 5.70 \\
$3 \%$ & 0.36 & 11.64 & 5.70 \\
$5 \%$ & 0.60 & 11.40 & 5.70 \\
$7 \%$ & 0.84 & 11.16 & 5.70 \\
\hline
\end{tabular}

To select the silane, a pilot study was performed using different quantities of saline monomer (y-MPS), at $3 \mathrm{wt} . \%, 5 \mathrm{wt} . \%$, and $10 \mathrm{wt} . \%$ Taking into account the results of this study and those of previous experiments, a $3 \mathrm{wt.} \%$ percentage weight of (y-MPS) was selected.

\subsubsection{Treating Surface of Fillers (Silanization)}

The surfaces of the fillers were modified using a $3 \mathrm{wt} . \%$ of silane coupling agent ( $\gamma$-MPS) before mixing with PMMA to promote improved chemical bonding between the fillers and the acrylic resin matrix [10,18]. A speed mixer (DAC 150.1 FVZK, High Wycombe, Buckinghamshire, UK) was used to mix $15 \mathrm{~g}$ of each filler with $70 \mathrm{~mL}$ of ethanol in a $100 \mathrm{~mL}$ plastic container for $10 \mathrm{~min}(1500 \mathrm{rpm})$, ensuring that the surfaces of the filler were adequately cleaned and coated evenly with ethanol solution. Then, $0.45 \mathrm{~g}(3 \mathrm{wt} . \%)$ of $\gamma$-MPS was added to the resultant suspension, and a magnetic stirrer (200 rpm over $2 \mathrm{~h}$ at room temperature) was employed to achieve a uniform consistency. The suspension was then refluxed for $4 \mathrm{~h}$ at $50^{\circ} \mathrm{C}$. When the reaction was complete, the resulting mixture was cooled, split into two equal parts, and placed into 50-mL plastic tubes sealed with a plastic lid. These tubes were then placed in a centrifuge (Heraeus, UK) and rotated for $20 \mathrm{~min}$ at $4500 \mathrm{rpm}$ and a temperature of $23^{\circ} \mathrm{C}$. The clear supernatant (containing both 
unreacted and condensate $\gamma$-MPS) was then decanted, leaving the sediment behind. The sediment comprised filler silanized with $\gamma$-MPS; this element comprises the centrifuged sample. The plastic tubes were then covered with perforated aluminium foil and placed into the Genevac machine (Genevac EZ-2 series, SP Scientific Company, UK) for drying for $3 \mathrm{~h}$ at $50{ }^{\circ} \mathrm{C}$, thus allowing solvent evaporation. This process produced the silanized fillers.

\subsubsection{Combining Nanoparticles and E-Glass Fibre with PMMA/MMA}

An electronic balance (Ohaus Analytical, Parsippany, NJ, USA) was employed to weigh conventional heat-polymerized powder and different quantities of silanized fillers. The silanized $\mathrm{ZrO}_{2}$ nanoparticles were placed in a speed mixer with the MMA monomer for $10 \mathrm{~min}$ at $1500 \mathrm{rpm}$; this allowed a homogenous suspension to form and avoided aggregation of $\mathrm{ZrO}_{2}$. The resultant product was regarded as the modified monomer. For each group, the modified monomer was mixed with PMMA powder in a ratio of $21 \mathrm{~g}$ powder and $10 \mathrm{~mL}$ modified monomer as per manufacturer's guidelines. As such, the ratio of mixing acrylic resin/filler to monomer was $12 \mathrm{~g}$ powder/filler to $5.7 \mathrm{~mL}$ monomer in each mould. This process was then repeated with the $\mathrm{TiO}_{2}$ nanoparticles.

To mix PMMA/MMA with silanized E-glass fibres, an identical powder/monomer ratio of $12 \mathrm{~g}$ to $5.7 \mathrm{~mL}$ was also employed. The necessary quantity of chopped E-glass fibres were dampened using $4.3 \mathrm{~mL}$ of MMA. These fibres, which were bundled together, were spread out and carefully manipulated by hand to allow for thorough saturation. Subsequently, $0.400 \mathrm{~g}$ of the PMMA powder was added to the liquid and mixed for $10 \mathrm{~s}$. This was done six times to make sure that the materials blended properly. The mixture was then stirred for 2 min longer to make sure that the chopped fibres adequately embedded in the MMA matrix. It could then be seen that the fibres were well distributed throughout the liquid. Finally, the remaining resin powder required (9.6 g) was added to this mixture of E-glass fibre and PMMA, and then the last of the monomer (MMA) liquid (1.4 mL) was added.

With both mixing methods, the mixture of PMMA/MMA and filler was stirred with a spatula for approximately a minute to make sure that the monomer moistened all powder and filler. An appropriate container was used that ensured the monomer could not evaporate. After around $20 \mathrm{~min}$ at room temperature, a packing (dough-like) consistency resulted. Having reached this stage, the resultant dough was manipulated by hand into the mould that was painted with a thin coating of separating medium to prevent the dough from attaching to the mould during the polymerization process. The mould was then closed and placed in a hydraulic press (Sirio Dental, Meldola (FC), Italy); the force was gradually increased to $10.34 \mathrm{MPa}$. Then, the mould was placed in a clamp that ensured a tight seal for final closure. The mould and clamp were then placed under water in a curing unit (Wassermann Dental-Maschinen $\mathrm{GmbH}$, Hamburg, Germany), starting gradually from room temperature to $74{ }^{\circ} \mathrm{C}$ for $90 \mathrm{~min}$, followed by $30 \mathrm{~min}$ at $95^{\circ} \mathrm{C}$. On completion of the polymerization cycle, the mould was allowed to cool for $30 \mathrm{~min}$ at room temperature before opening, to reduce the chances of the specimens becoming stressed or warped. Finally, the specimens were taken out of the mould and abraded with series of silicon carbide papers (Buehler Ltd. Esslingen, Germany). Then the surfaces of the specimens were polished and smoothened using a lapping machine (MetaServ 250, Buehler Ltd. Esslingen, Germany).

\subsection{Mechanical Measurments Procedures}

\subsubsection{Flexural Strength Measurement}

Ten specimens from each group were stored separately in distilled water in an incubator at $37^{\circ} \mathrm{C}$ for 7 days before testing in line with ISO 1567 standard [38]. The flexural strength of the specimens was then measured using a three-point bending test performed in a universal testing machine (INSTRON 3344.Software: Bluehill 3, Norwood, MA, USA) according to the ISO 1567 standard [38]. Upon removal from the distilled water, each specimen was immediately placed at a parallel angle on two supports. The distance between the two supports was kept at $50 \mathrm{~mm}$. At room temperature, a $500 \mathrm{~N}$ load cell was applied 
vertically at the specimen midpoint at a crosshead speed of $5 \mathrm{~mm} / \mathrm{min}$ until fracture occurred. The equation shown below (Equation (1)) was used to calculate the flexural strength $\left(\sigma_{f}\right)$ of each specimen in MPa:

$$
\sigma_{f}=\frac{3 \mathrm{FL}}{2 \mathrm{bh}^{2}}
$$

where, $\mathrm{F}$ is the peak load applied to the specimen in Newtons $(\mathrm{N}), \mathrm{L}$ is the support span length $(50 \mathrm{~mm}), \mathrm{b}$ is the specimen width in $\mathrm{mm}$, and $\mathrm{h}$ is the specimen thickness in $\mathrm{mm}$.

\subsubsection{Surface Hardness Measurement}

Hardness was assessed with a digital microhardness tester (FM-700, Future Tech Corp., Kawasaki, Japan). An indenter point in the form of a square-based pyramid was applied at a load of $300 \mathrm{~g}$ for $15 \mathrm{~s}$ at room temperature after 7 days of storage at $37^{\circ} \mathrm{C}$. Five indentations were made at different points along each specimen on the same surface side, with a minimum distance of $1 \mathrm{~mm}$ between any two indentations. The mean hardness value of each specimen group was then calculated. The Vickers microhardness (HVN) value was calculated using Equation (2).

$$
\mathrm{HV}=1.8544 \frac{\mathrm{F}}{\mathrm{d}^{2}}
$$

where, $\mathrm{F}$ is the applied load in kilogram-force (kgf), and $\mathrm{d}$ is the arithmetic mean of the two diagonals, $d_{1}$ and $d_{2}$ from surface area of the indentation in $\mathrm{mm}$.

\subsection{Fracture Surface Analysis}

A scanning electron microscope SEM (Carl Zeiss Ltd., 40 VP, Smart SEM, Cambridge, UK) was employed to study the fractured surface of the control group specimen. Specimens at $7 \mathrm{wt} . \%$ concentrations from each subgroup were selected at the point of loading after the flexural strength test to assess the adhesion of fillers with the resin matrix, possible porosity and other defects. The specimens were mounted onto aluminium stubs and sputter-coated with gold before a secondary electron detector at an acceleration voltage of $2.0 \mathrm{kV}$ was used to perform the SEM visualization at different magnifications. The shape and size distribution of the pure PMMA powder and fillers alone were also examined.

\subsection{Statistical Analysis}

The flexural strength and surface hardness data were statistically analysed using a statistical software (SPSS statistics version 25, IBM, New York, NY, USA). According to the findings of the Levene and Shapiro-Wilk tests, the p-values were not statistically significant, indicating that the data were normally distributed with homogeneous variance. A one-way analysis of variance (ANOVA) was performed at a $p \leq 0.05$ significance level with a Tukey post-hoc test.

\section{Results}

\subsection{Physical Characteristics of Particles}

As shown in Figure 1A, according to the outputs of the SEM analysis, the particle size of the PMMA powder ranged from $10 \mu \mathrm{m}$ to $90 \mu \mathrm{m}$, with a mean size around $50 \mu \mathrm{m}$. The average size of the $\mathrm{ZrO}_{2}$ nanoparticles ranged between $25 \mathrm{~nm}$ and $50 \mathrm{~nm}$ for the individual particles and $150 \mathrm{~nm}$ to $300 \mathrm{~nm}$ for the clusters, as can be observed in Figure 1B. The average size of the $\mathrm{TiO}_{2}$ nanoparticles ranged from $20 \mathrm{~nm}$ to $30 \mathrm{~nm}$ for the individual particles and $100 \mathrm{~nm}$ to $300 \mathrm{~nm}$ for the clusters, as can be seen in Figure 1C. The length and diameter of the E-glass fibres were between $2.5-3.2 \mathrm{~mm}$ and $14-18 \mu \mathrm{m}$ respectively, as shown in Figure 1D. 


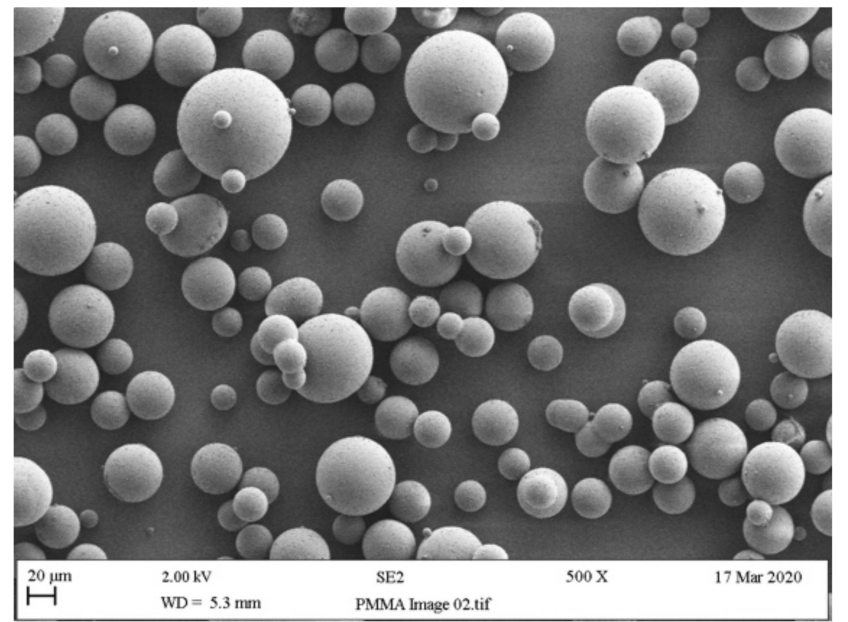

(A)

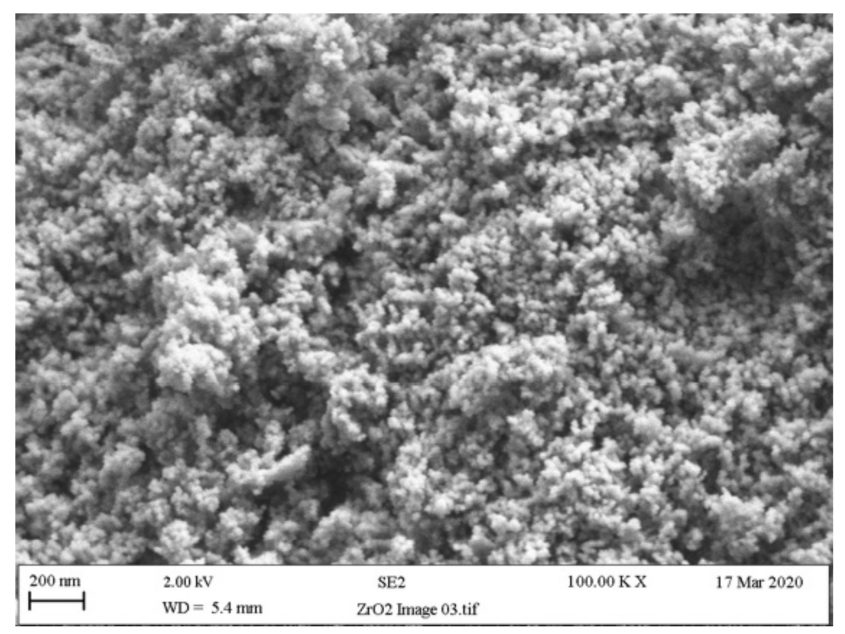

(C)



(B)

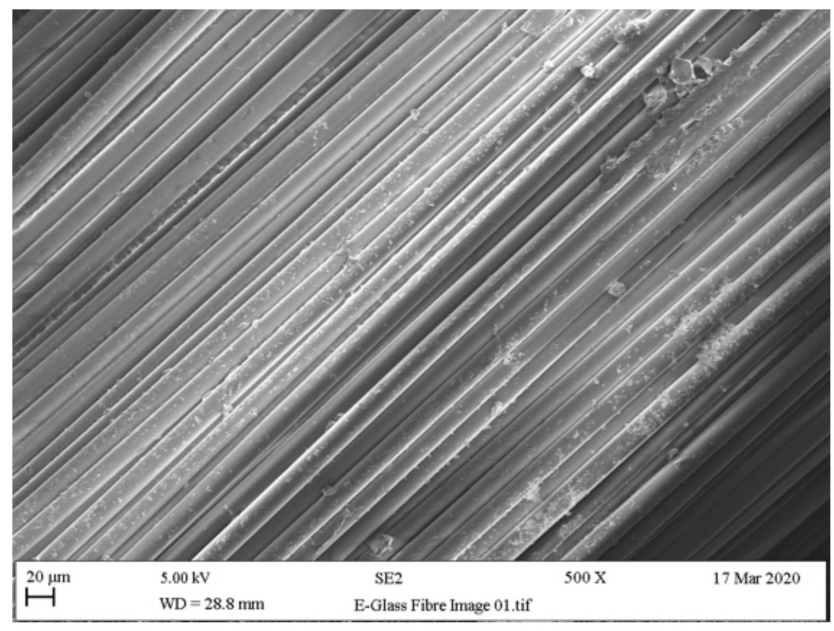

(D)

Figure 1. Particle/fibre size of (A) PMMA powder, (B) $\mathrm{ZrO}_{2}$ nanoparticles, (C) $\mathrm{TiO}_{2}$ nanoparticles and (D) E-glass fibre.

\subsection{Flexural Strength}

Figure 2 and Table 4 present the means and standard deviations of flexural strength across the tested groups. The outputs of the ANOVA revealed that there was a statistically significant difference in the flexural strength of the specimens in the E-glass fibre and the $\mathrm{ZrO}_{2}$ nanoparticle groups when compared to the specimens in Group $\mathrm{C}(p<0.05)$. However, there was no statistically significant difference $(p>0.05)$ between the flexural strength of the specimens reinforced with $\mathrm{TiO}_{2}$ nanoparticles groups and those in Group C. The results of the Tukey test revealed that the significant differences $(p<0.05)$ in flexural strength was observed in the specimen groups Z3, E5, and E7 (98.4 $\pm 8.3 \mathrm{MPa}$, $101.2 \pm 10.4 \mathrm{MPa}$ and $105 \pm 10.6 \mathrm{MPa})$ compared to those in Group C $(89.2 \pm 6.3 \mathrm{MPa})$. The highest flexural strength value was observed in Group E7 (105 $\pm 10.6 \mathrm{MPa})$, while Group T7 (83.5 $\pm 7.2 \mathrm{MPa})$ had the lowest flexural strength among the reinforced groups.

Of the groups that were reinforced with $\mathrm{ZrO}_{2}$ nanoparticles, there was a significant difference $(p<0.05)$ in flexural strength between Group Z3 and Group Z7. Overall, the mean flexural strength in Groups Z1.5 and Z3 increased to 92.6 and 98.4 MPa respectively. However, the mean flexural strength of the specimens in the Z 5 group slightly dropped to $95.8 \mathrm{MPa}$, while that of Group Z7 dropped sharply to $88.3 \mathrm{MPa}$ and exhibited a lower flexural strength than that in Group C. However, this drop in strength values was not statistically significant $(p>0.05)$. 


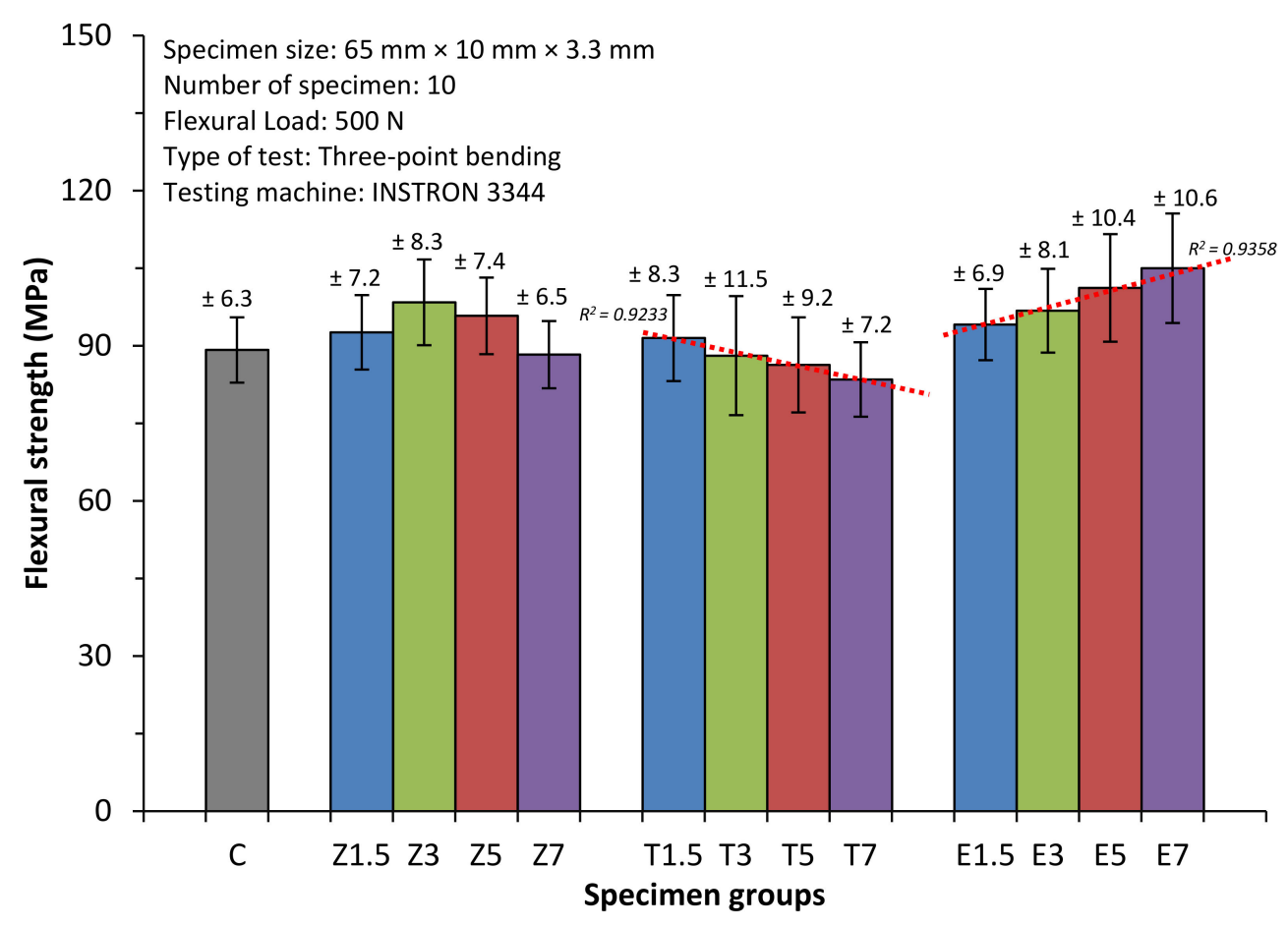

Figure 2. Mean flexural strength of all specimen groups with standard deviation values.

Table 4. Mean and standard deviation (SD) of flexural strength and surface hardness values for the tested groups.

\begin{tabular}{|c|c|c|c|}
\hline \multicolumn{2}{|c|}{ Group } & \multirow{2}{*}{$\begin{array}{c}\begin{array}{c}\text { Flexural Strength (MPa) } \\
\text { Mean } \pm \text { SD }\end{array} \\
89.2(6.3) \text { ACD * }\end{array}$} & \multirow{2}{*}{$\begin{array}{c}\begin{array}{c}\text { Surface Hardness } \\
\left(\mathbf{H V}_{\mathbf{0 . 3 0} \mathbf{~ K g}}\right) \text { Mean } \pm \mathbf{S D}\end{array} \\
17.3(0.49) \mathrm{AD}\end{array}$} \\
\hline Control & $\mathrm{C}$ & & \\
\hline \multirow{4}{*}{$\mathrm{ZrO}_{2}$} & Z1.5 & $92.6(7.2) \mathrm{AB}$ & $17.9(0.58) \mathrm{A}$ \\
\hline & $\mathrm{Z3}$ & $98.4(8.3)^{\mathrm{B}}$ & $18.7(0.55)^{B}$ \\
\hline & Z5 & $95.8(7.4) \mathrm{AB}$ & $19.1(0.58)^{B C}$ \\
\hline & $\mathrm{Z7}$ & $88.3(6.5)^{\mathrm{A}}$ & $19.6(0.70)^{C}$ \\
\hline \multirow{4}{*}{$\mathrm{TiO}_{2}$} & $\mathrm{~T} 1.5$ & $91.5(8.3)^{C}$ & $17.0(0.63) \mathrm{DE}$ \\
\hline & $\mathrm{T} 3$ & $88.1(11.5)^{C}$ & $18.1(0.66)^{\mathrm{E}}$ \\
\hline & T5 & $86.3(9.2)^{C}$ & $18.3(0.56)^{\mathrm{E}}$ \\
\hline & $\mathrm{T} 7$ & $83.5(7.2)^{C}$ & $18.8(0.67)^{\mathrm{E}}$ \\
\hline \multirow{4}{*}{ E-glass fibre } & E1.5 & $94.1(6.9) \mathrm{DE}$ & $18.5(0.85)^{\mathrm{F}}$ \\
\hline & E3 & $96.8(8.1) \mathrm{DE}$ & $19.2(0.69)^{\mathrm{FG}}$ \\
\hline & E5 & $101.2(10.4)^{\mathrm{E}}$ & $19.8(0.58) \mathrm{GH}$ \\
\hline & E7 & $105(10.6)^{\mathrm{E}}$ & $20.5(1.0)^{\mathrm{H}}$ \\
\hline
\end{tabular}

* Similar superscript letters in the same column indicate no significant difference between each of the reinforced groups and the PMMA acrylic resin control group $(p>0.05)$.

As the concentration at various ratios $1.5 \mathrm{wt} . \%, 3 \mathrm{wt} . \%, 5 \mathrm{wt} . \%$, and $7 \mathrm{wt} . \%$ of filler increased, the flexural strength of the specimens reinforced with $\mathrm{TiO}_{2}$ nanoparticles gradually reduced from $91.5 \pm 8.3,88.1 \pm 11.5,86.3 \pm 9.2$ to $83.5 \pm 7.2 \mathrm{MPa}$ respectively. However, no statistically significant $(p>0.05)$ difference was found between the specimens in these groups. A negative correlation $\left(\mathrm{R}^{2}=0.9233\right)$ was found between the strength and the $\mathrm{TiO}_{2}$ particle concentrations.

The flexural strength of the groups modified with E-glass fibre was positively correlated $\left(R^{2}=0.9358\right)$ with the E-glass concentrations, i.e., E1.5 (94.1 $\left.\pm 6.9 \mathrm{MPa}\right)$ had the lowest flexural strength, followed by E3, E5 and finally E7. No significant differences ( $p>0.05)$ were observed across the E-glass reinforced groups. 


\subsection{Surface Hardness}

Figure 3 and Table 4 present surface hardness of the specimens with their mean values and standard deviations. The outcomes of the ANOVA analysis revealed that all reinforced groups exhibited significantly higher Vickers hardness than Group C $(p<0.05)$. However, the findings of the Tukey test indicated that there were no significant differences in surface hardness between the Z1.5 $\left(17.9 \pm 0.58 \mathrm{HV}_{0.30 \mathrm{Kg}}\right)$ and $\mathrm{T} 1.5\left(17 \pm 0.63 \mathrm{HV}_{0.30 \mathrm{Kg}}\right)$ nanoparticles groups and Group C $\left(17.3 \pm 0.49 \mathrm{HV}_{0.30 \mathrm{Kg}} ; p>0.05\right)$. The highest mean Vickers hardness was found in Group E7 $\left(20.5 \pm 1 \mathrm{HV}_{0.30 \mathrm{Kg}}\right)$, while the lowest was observed in Group T1.5. When the ratios of filler/fibre were increased, the mean Vickers hardness values positivity increased in $\mathrm{ZrO}_{2}\left(R^{2}=0.9854\right), \mathrm{TiO}_{2}\left(R^{2}=0.9917\right)$ and E-glass $\left(R^{2}=0.8674\right)$ reinforced groups.



Figure 3. Mean surface hardness of all specimen groups with standard deviation values.

Within the groups reinforced with $\mathrm{ZrO}_{2}$ nanoparticles, the Vickers hardness of the specimens in groups Z3, Z5, and Z7 was $18.7 \pm 0.55,19.1 \pm 0.58$ and $19.6 \pm 0.7 \mathrm{HV}_{0.30 \mathrm{Kg}}$ respectively, which were significantly higher than that of Group Z1.5. Furthermore, the hardness of the specimens in Group Z7 was statistically higher than those in Group Z3. However, no significant difference in hardness $(p>0.05)$ was found between Groups Z5/Z3 or Z5/Z7 in terms of hardness.

Of the groups reinforced with $\mathrm{TiO}_{2}$ nanoparticles, the Vickers hardness in Group T1.5 decreased significantly than that of the $\mathrm{TiO}_{2}$ subgroups. No statistically significant difference in hardness was observed between the T3/T5 or T3/T7 groups or group T5/T7.

With regard to the groups reinforced with E-glass fibre, Group E7 demonstrated a significantly $(p<0.05)$ higher Vickers hardness than Groups E1.5 and E3. A further significant difference $(p<0.05)$ was observed between the hardness of the specimens in Group E5 and those in Group E1.5. There were no significant differences $(p>0.05)$ in mean Vickers hardness between Groups E1.5/E3, E3/E5, or E5/E7.

\subsection{Microstructural Characteristics}

The fractured surface of pure PMMA specimens, Groups $C$ displayed a ductile type failure behaviour with irregular areas and small nanopores as shown in Figure 4A. The nanocomposite fractured surface showed signs of particle clustering with small voids 
(Figure 4B, Z7) and (Figure 4C, T7). This indicated that the distribution of the nanoparticles was not uniform particularly at high particle concentration (i.e., $7 \mathrm{wt} . \%$ ). Glass fibres are seen embedded within the PMMA matrix either as a single fibre or in bundles Figure $4 \mathrm{D}$, E7). Brittle fracture of glass fibres with small gap between the fibre and matrix were clearly visible.

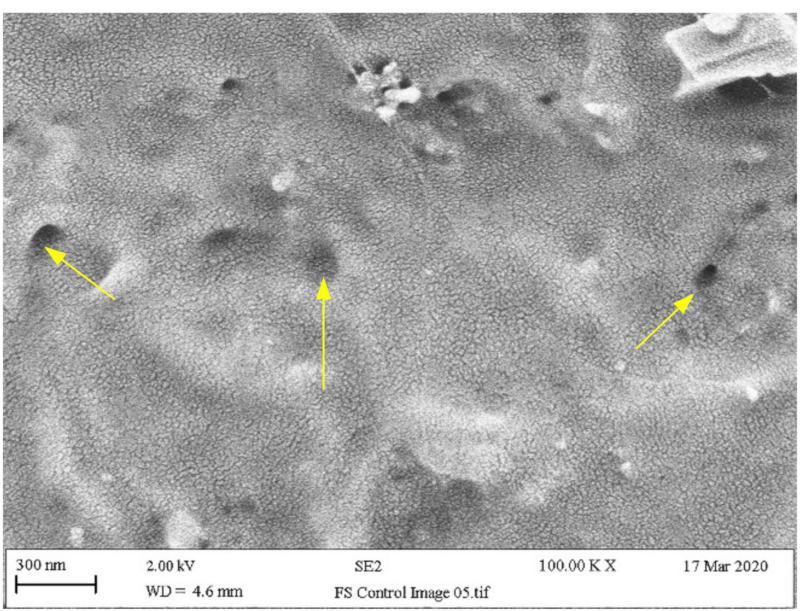

(A)

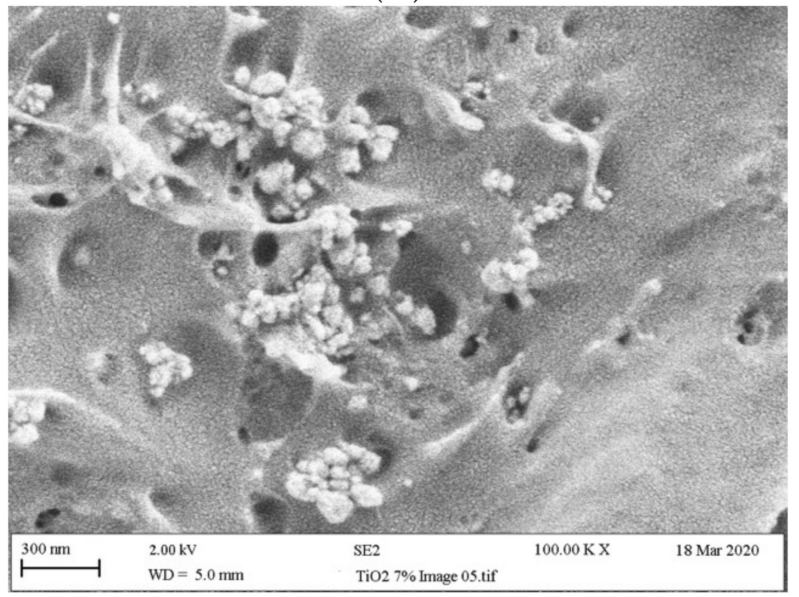

(C)

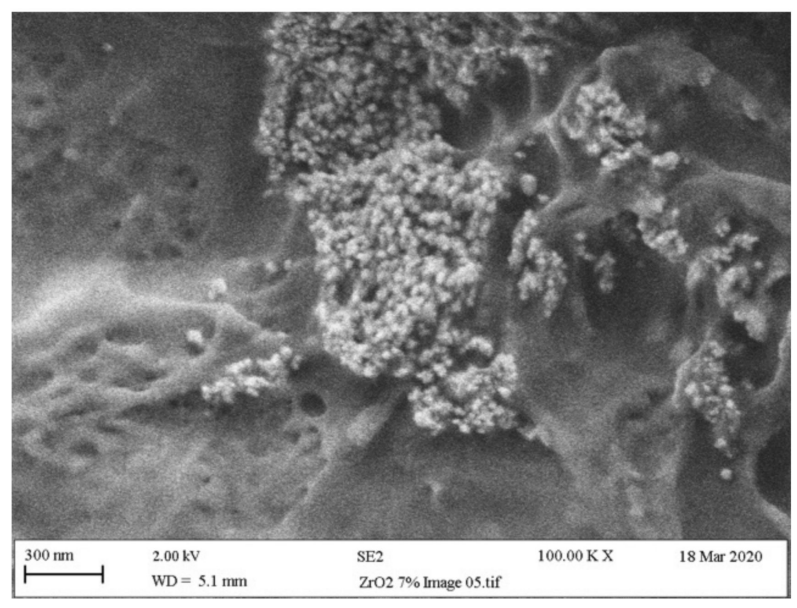

(B)

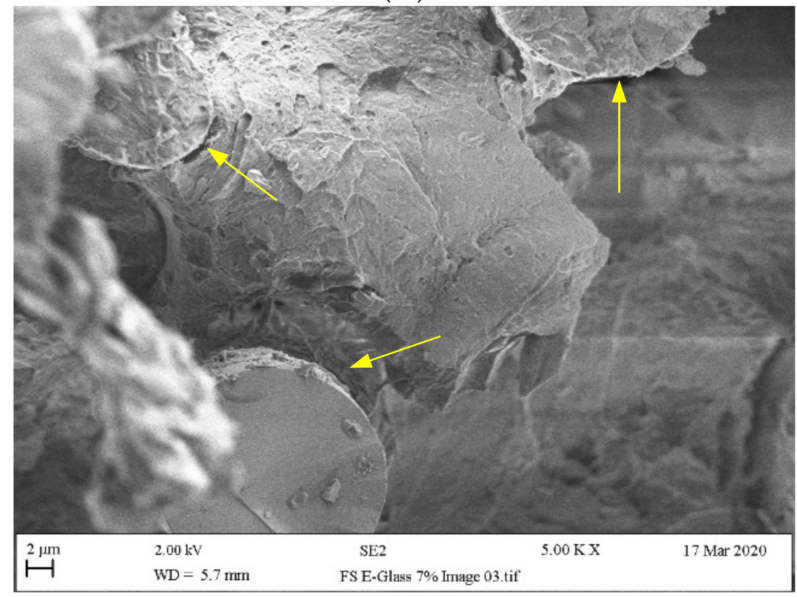

(D)

Figure 4. Fractured surfaces of (A) pure heat-cured PMMA (arrow showing pores) and reinforced composites (Group C) with (B) $\mathrm{ZrO}_{2}$ nanoparticle (Z7), (C) $\mathrm{TiO}_{2}$ nanoparticle (T7), and (D) E-glass fibre (E7; arrow showing gap between fibre and matrix).

\section{Discussions}

The null hypothesis was rejected on the basis that variations on both the flexural strength and the surface hardness of the PMMA resins were observed after they were filled with zirconium oxide, titanium oxide nanoparticles, and E-glass fibre.

Various factors were of significance during the process of incorporating filler into PMMA: The distribution of the polymer matrix, the shape and size of the filler, and the level of bonding between the filler and the matrix $[10,26,41]$. The filler needs to be small enough to produce a homogenous mixtures and can penetrate between the linear macromolecule chains, thereby restricting their movement $[9,42]$. Previous studies have concluded that the percentage filler should be sufficiently low to ensure the fillers are embedded in the resin [15,18]. In this study, we used sizes of approximately $50 \mathrm{~nm} \mathrm{ZrO}, 25 \mathrm{~nm} \mathrm{TiO}$, and $15 \mu \mathrm{m}$ E-glass fibres that were combined with $90 \mu \mathrm{m}$ acrylic powder. This prevented a heterogeneous mixture from forming and allowed the nanoparticles to fill any pores that had formed between the polymer particles; as such, the polymer chain movement was inhibited [15]. 
The flexural strength of dentures plays a vital role in understanding how well a resin will perform under the stress of mastication/chewing [30,35]. Previous studies have found that variations in the ratio of nanoparticles/fibres can have positive or negative impacts on the surface hardness and flexural strength of acrylic resins $[10,12,15,19,25]$. In the current study we found that the incorporation of $\mathrm{ZrO}_{2}$ nanofillers or E-glass fibre within the PMMA matrix enhanced the flexural strength of PMMA in comparison to the specimens in the control group. However, the addition of $\mathrm{TiO}_{2}$ nanoparticles to PMMA did not lead to any improvement in flexural strength. As can be observed in Table 4, the flexural strength values of the PMMA increased by $10.3 \%(p<0.05)$ when 3 wt. $\% \mathrm{ZrO}_{2}$ was added to the PMMA resin but it slightly decreased when 7 wt. $\% \mathrm{ZrO}_{2}$ was incorporated (1\%). The addition of $1.5 \mathrm{wt}$ \% and $5 \mathrm{wt} \% \mathrm{Z \textrm {rO } _ { 2 }}$ into PMMA also increased the flexural strength of the material; however, the difference was not statistically significant. Thus our proposal was that homogenized blending of fillers into a PMMA matrix might improve the strength of the material [11,42]. However, we observed that the higher ratios of particles led to appearances of clustering, which form spaces. The spaces could explain the decreased strength of the material and the non-homogeneous mixing $[7,12,37]$. This is supported by the SEM images presented in Figure 4B.

The outcomes of the current study are consistent with the results of previous studies that assessed the impact nano- $\mathrm{ZrO}_{2}$ has on the flexural strength of PMMA dentures $[18,43]$. Nejatian et al. [12] proved that the inclusion of silanated $\mathrm{ZrO}_{2}$ into heat-cured PMMA at $10 \mathrm{wt}$ \% reduced the flexural strength of PMMA denture. According to Ergun et al. [19] the addition of various ratios of nano- $\mathrm{ZrO}_{2}$ to heat-cured PMMA (5 wt. $\% 10 \mathrm{wt} . \%$, and $20 \mathrm{wt.} \%$ ) reduced the flexural strength of the material in comparison to the pure PMMA control group.

Nazirkar et al. [20] found that the flexural strength of the material decreased as the concentration of $\mathrm{TiO}_{2}$ increased. Karci et al. [15] also demonstrated that the flexural strength of three different polymerization systems of PMMA acrylic resin fell when a higher concentration of $\mathrm{TiO}_{2}$ nanoparticles was included in the resin (3-5 wt.\%). In contrast, Naji et al. [44] showed that the flexural strength of conventional $\mathrm{PMMA}_{\mathrm{M}}$ modified with $\mathrm{TiO}_{2}$ nanotubes at concentrations of $2.5 \mathrm{wt} . \%$ and $5 \mathrm{wt}$.\% were significantly higher than those of the control PMMA. In the current study we found that there was a negative correlation between an increase in $\mathrm{TiO}_{2}$ nanoparticle concentration and the flexural strength values of $\mathrm{PMMA} / \mathrm{TiO}_{2}$ composites. The reduction in flexural strength was observed when the $\mathrm{TiO}_{2}$ particles concentration exceeded $1.5 \mathrm{wt}$.\%. The SEM image (Figure 4C) revealed the presence of large porous structures, which could be attributed to agglomeration particles and the non-homogeneous distribution of particles in the PMMA matrix, leading to weak points in the structure $[12,21,45]$. Previous studies have reported that any hollow space in between the matrix discontinues the stress distribution and may contribute to the inferior mechanical performance of the $\mathrm{TiO}_{2}$ particle-reinforced PMMA $[12,46]$.

The research by Lee et al. [25] revealed that the flexural strength of the PMMA significantly increased when the concentrations of silane-treated glass fibres were maintained $6 \mathrm{wt} . \%$ and 9 wt.\%. Yu et al. [10] also concluded that increasing the concentration of glass fibres significantly increased the flexural strength of the base resin. These findings are in agreement with the results obtained in the present study, which showed that the highest flexural strength values of PMMA/E-glass composites were at the $7 \mathrm{wt}$ \% ratio. The PMMA/E-glass matrix interaction is clearly depicted in the SEM image presented in Figure 4D. We observed that the fibres surround the PMMA matrix. This indicated that a good chemical bond had formed between the fibre and the matrix due to the effect the silane treatment had on the fibre $[37,41]$. This could explain the superior fracture resistance the E-glass fibre reinforced group exhibited in comparison to the other tested polymer composites. Furthermore, due to the level of effective bonding between the fibre and the matrix, upon the complex flexural loading, the fibres might have acted as stress-bearing areas, and slow equal stress distribution may have generated an improved flexural strength and resistance to fibre fracture $[10,37]$. 
The Vickers microhardness values in Table 2 indicated that the PMMA reinforced with the three filler materials had a higher surface hardness than the specimens in the control group, with exception of the groups Z1.5 and T1.5. The specimens in Group T1.5 exhibited an insignificantly lower surface hardness than those in the control group. At the highest concentration, the E-glass fillers had increased the hardness of the composites by the highest amount followed by the $\mathrm{ZrO}_{2}$ and then the $\mathrm{TiO}_{2}$. This result is in agreement with previous research, which has found that the addition of glass fibre $[9,36], \mathrm{ZrO}_{2}[5,18]$ and $\mathrm{TiO}_{2}[12,15]$ nanoparticles in PMMA at different concentrations statistically improved the surface hardness of PMMA denture bases. The increase in filler content enhanced the surface hardness up to the point at which the optimal level was achieved [22]. This can be attributed to the fact that, when the optimal level of filler for the matrix is reached through magnetic stirrers and speed mixers, the agglomeration of the composite is reduced [5,22].

Generally, the most viable explanation for the increase in flexural strength and surface hardness of PMMA/filler observed in the current study was the use of the 3wt.\% silane coupling agent, which helped to improve the chemical bond between the filler and the PMMA matrix $[9,18]$. This entails that a greater amount of energy is required to break the chemical bonds that form between the materials [5,30]. A further explanation for this improvement was the homogeneous filler distribution that was achieved by using an ultrasonic speed mixer to combine the filler particles in the monomer. However, the decreased flexural strength observed at the high percentage of nanoparticles could be attributed to the higher levels of filler in the mix [12,22]. One explanation for this could be the fact that flexural strength is a bulk property in comparison to surface hardness. Once the saturation point has been reached, the resin cannot absorb any further filler. Adding more filler after the resin reaches the saturation point disturbs the continuity of the resin matrix and, subsequently, weakens the properties of the composite materials $[5,13]$.

\section{Conclusions}

The optimal filler concentrations for reinforcing PMMA denture base resins from the flexural strength perspective were 3-5 wt. $\% \mathrm{ZrO}_{2}, 1.5 \mathrm{wt}$ \% $\mathrm{TiO}_{2}$, and 3-7\% wt.\% E-glass fibre. This study found that the surface hardness of the reinforced PMMA generally increased as the content of the fillers increased. A significant increase in the hardness of the composites was observed for all the fillers at all concentrations with exception of the $1.5 \mathrm{wt}$ \% concentration of $\mathrm{TiO}_{2}$ and $\mathrm{ZrO}_{2}$ nanoparticles. Therefore, a filler concentration greater than $3 \mathrm{wt}$ \% could be considered suitable for producing composites that offer a significantly higher hardness. The findings of this study indicated that the addition of Eglass fibre to PMMA delivered the greatest improvement in terms of mechanical properties, followed by $\mathrm{ZrO}_{2}$ and then $\mathrm{TiO}_{2}$. Thus, improving the mechanical properties of PMMA denture bases through the use of the fibre and filler can produce dentures that can achieve longer clinical service.

Author Contributions: Conceptualization, N.S. and A.A.; methodology, N.S., J.Y., A.A., S.Z. and J.H.; validation, A.A.; formal analysis, A.A., J.H., N.S. and J.Y.; investigation, A.A.; data curation, A.A.; writing—original draft preparation, A.A. and J.H.; writing—review and editing, N.S., J.Y., J.H., A.A. and S.Z.; visualization, A.A. and J.H.; supervision, N.S., J.Y. and J.H.; project administration, N.S. All authors have read and agreed to the published version of the manuscript.

Funding: This research received no external funding.

Institutional Review Board Statement: Not applicable.

Informed Consent Statement: Not applicable.

Data Availability Statement: The data presented in this study are available within the article.

Acknowledgments: The authors would like to thank the King Saud University for providing financial support for PhD study; Brian Daber from Department of Dental Biomaterial, University of Manchester; Michael Green and Hayley Andrews from the Faculty of Science and Engineering, Manchester Metropolitan University, for supporting the experimental work. 
Conflicts of Interest: The authors declare no conflict of interest.

\section{References}

1. Bacali, C.; Badea, M.; Moldovan, M.; Sarosi, C.; Nastase, V.; Baldea, I.; Chiorean, R.S.; Constantiniuc, M. The Influence of Graphene in Improvement of Physico-Mechanical Properties in PMMA Denture Base Resins. Materials 2019, 12, 2335. [CrossRef] [PubMed]

2. Machado, C.; Sanchez, E.; Azer, S.S.; Uribe, J.M. Comparative Study of the Transverse Strength of Three Denture Base Materials. J. Dent. 2007, 35, 930-933. [CrossRef]

3. Polyzois, G.L.; Tarantili, P.A.; Frangou, M.J.; Andreopoulos, A.G. Fracture Force, Deflection at Fracture, and Toughness of Repaired Denture Resin Subjected to Microwave Polymerization or Reinforced with Wire or Glass Fiber. J. Prosthet. Dent. 2001, 86, 613-619. [CrossRef]

4. Gungor, H.; Gundogdu, M.; Alkurt, M.; Duymus, Z.Y. Effect of Polymerization Cycles on Flexural Strengths and Microhardness of Different Denture Base Materials. Dent. Mater. J. 2017, 36, 168-173. [CrossRef]

5. Zhang, X.-Y.; Zhang, X.-J.; Huang, Z.-L.; Zhu, B.-S.; Chen, R.-R. Hybrid Effects of Zirconia Nanoparticles with Aluminum Borate Whiskers on Mechanical Properties of Denture Base Resin PMMA. Dent. Mater. J. 2014, 33, 141-146. [CrossRef]

6. So, Y.C.; Tsoi, J.K.-H.; Matinlinna, J.P. A New Approach to Cure and Reinforce Cold-Cured Acrylics. Silicon 2012, 4, 209-220. [CrossRef]

7. Chladek, G.; Pakiela, K.; Pakiela, W.; Zmudzki, J.; Adamiak, M.; Krawczyk, C. Effect of Antibacterial Silver-Releasing Filler on the Physicochemical Properties of Poly (Methyl Methacrylate) Denture Base Material. Materials 2019, 12, 4146. [CrossRef]

8. Totu, E.E.; Nechifor, A.C.; Nechifor, G.; Aboul-Enein, H.Y.; Cristache, C.M. Poly (Methyl Methacrylate) with TiO 2 Nanoparticles Inclusion for Stereolitographic Complete Denture Manufacturing-the Fututre in Dental Care for Elderly Edentulous Patients. J. Dent. 2017, 59, 68-77. [CrossRef] [PubMed]

9. Gad, M.M.; Rahoma, A.; Al-Thobity, A.M. Effect of Polymerization Technique and Glass Fiber Addition on the Surface Roughness and Hardness of PMMA Denture Base Material. Dent. Mater. J. 2018, 37, 746-753. [CrossRef]

10. Yu, S.-H.; Lee, Y.; Oh, S.; Cho, H.-W.; Oda, Y.; Bae, J.-M. Reinforcing Effects of Different Fibers on Denture Base Resin Based on the Fiber Type, Concentration, and Combination. Dent. Mater. J. 2012, 31, 1039-1046. [CrossRef] [PubMed]

11. Zidan, S.; Silikas, N.; Haider, J.; Alhotan, A.; Jahantigh, J.; Yates, J. Evaluation of Equivalent Flexural Strength for Complete Removable Dentures Made of Zirconia-Impregnated PMMA Nanocomposites. Materials 2020, 13, 2580. [CrossRef] [PubMed]

12. Nejatian, T.; Nathwani, N.; Taylor, L.; Sefat, F. Denture Base Composites: Effect of Surface Modified Nano-and Micro-Particulates on Mechanical Properties of Polymethyl Methacrylate. Materials 2020, 13, 307. [CrossRef]

13. Yang, A.; Zhao, D.; Wu, Y.; Xu, C. Effect of Polyimide Addition on Mechanical Properties of PMMA-Based Denture Material. Dent. Mater. J. 2017, 36, 560-565. [CrossRef] [PubMed]

14. John, J.; Gangadhar, S.A.; Shah, I. Flexural Strength of Heat-Polymerized Polymethyl Methacrylate Denture Resin Reinforced with Glass, Aramid, or Nylon Fibers. J. Prosthet. Dent. 2001, 86, 424-427. [CrossRef] [PubMed]

15. Karci, M.; Demir, N.; Yazman, S. Evaluation of Flexural Strength of Different Denture Base Materials Reinforced with Different Nanoparticles. J. Prosthodont. 2019, 28, 572-579. [CrossRef] [PubMed]

16. Ilie, N.; Hilton, T.; Heintze, S.; Hickel, R.; Watts, D.; Silikas, N.; Stansbury, J.; Cadenaro, M.; Ferracane, J. Academy of Dental Materials Guidance-Resin Composites: Part I-Mechanical Properties. Dent. Mater. 2017, 33, 880-894. [CrossRef]

17. Kim, S.-H.; Watts, D.C. The Effect of Reinforcement with Woven E-Glass Fibers on the Impact Strength of Complete Dentures Fabricated with High-Impact Acrylic Resin. J. Prosthet. Dent. 2004, 91, 274-280. [CrossRef]

18. Zidan, S.; Silikas, N.; Alhotan, A.; Haider, J.; Yates, J. Investigating the Mechanical Properties of $\mathrm{ZrO}_{2}$-Impregnated PMMA Nanocomposite for Denture-Based Applications. Materials 2019, 12, 1344. [CrossRef]

19. Ergun, G.; Sahin, Z.; Ataol, A.S. The Effects of Adding Various Ratios of Zirconium Oxide Nanoparticles to Poly (Methyl Methacrylate) on Physical and Mechanical Properties. J. Oral Sci. 2018, 60, 304-315. [CrossRef]

20. Nazirkar, G.; Bhanushali, S.; Singh, S.; Pattanaik, B.; Raj, N. Effect of Anatase Titanium Dioxide Nanoparticles on the Flexural Strength of Heat Cured Poly Methyl Methacrylate Resins: An in-Vitro Study. J. Indian Prosthodont. Soc. 2014, 14, 144-149. [CrossRef]

21. Kul, E.; Aladag, L.I.; Yesildal, R. Evaluation of Thermal Conductivity and Flexural Strength Properties of Poly (Methyl Methacrylate) Denture Base Material Reinforced with Different Fillers. J. Prosthet. Dent. 2016, 116, 803-810. [CrossRef] [PubMed]

22. Zhang, X.; Zhang, X.; Zhu, B.; Lin, K.; Chang, J. Mechanical and Thermal Properties of Denture PMMA Reinforced with Silanized Aluminum Borate Whiskers. Dent. Mater. J. 2012, 31, 903-908. [CrossRef] [PubMed]

23. Kumar, G.; Nigam, A.; Naeem, A.; Gaur, A.; Pandey, K.; Deora, A. Reinforcing Heat-Cured Poly-Methyl-Methacrylate Resins Using Fibers of Glass, Polyaramid, and Nylon: An in Vitro Study. J. Contemp. Dent. Pract. 2016, 17, 948-952. [CrossRef] [PubMed]

24. Takahashi, Y.; Yoshida, K.; Shimizu, H. Effect of Location of Glass Fiber-Reinforced Composite Reinforcement on the Flexural Properties of a Maxillary Complete Denture in Vitro. Acta Odontol. Scand. 2011, 69, 215-221. [CrossRef] [PubMed]

25. Lee, S.-I.; Kim, C.-W.; Lim, Y.-J.; Kim, M.-J.; Yun, S.-D. Strength of Glass Fiber Reinforced PMMA Resin and Surface Roughness Change after Abrasion Test. J. Korean Acad. Prosthodont. 2007, 45, 310-320.

26. Asar, N.V.; Albayrak, H.; Korkmaz, T.; Turkyilmaz, I. Influence of Various Metal Oxides on Mechanical and Physical Properties of Heat-Cured Polymethyl Methacrylate Denture Base Resins. J. Adv. Prosthodont. 2013, 5, 241-247. [CrossRef] [PubMed] 
27. Vallittu, P.K. Glass Fiber Reinforcement in Repaired Acrylic Resin Removable Dentures: Preliminary Results of a Clinical Study. Quintessence Int. 1997, 28, 39-44.

28. Gurbuz, O.; Dikbas, I.; Unalan, F. Fatigue Resistance of Acrylic Resin Denture Base Material Reinforced with E-Glass Fibres. Gerodontology 2012, 29, e710-e714. [CrossRef]

29. Zhang, M.; Matinlinna, J.P. E-Glass Fiber Reinforced Composites in Dental Applications. Silicon 2012, 4, 73-78. [CrossRef]

30. Cevik, P.; Yildirim-Bicer, A.Z. The Effect of Silica and Prepolymer Nanoparticles on the Mechanical Properties of Denture Base Acrylic Resin. J. Prosthodont. 2018, 27, 763-770. [CrossRef]

31. Denry, I.; Kelly, J.R. State of The Art of Zirconia for Dental Applications. Dent. Mater. 2008, 24, 299-307. [CrossRef] [PubMed]

32. Bona, A.D.; Pecho, O.E.; Alessandretti, R. Zirconia as a Dental Biomaterial. Materials 2015, 8, 4978-4991. [CrossRef]

33. Shahmiri, R.; Standard, O.C.; Hart, J.N.; Sorrell, C.C. Optical Properties of Zirconia Ceramics for Esthetic Dental Restorations: A Systematic Review. J. Prosthet. Dent. 2018, 119, 36-46. [CrossRef] [PubMed]

34. Alrahlah, A.; Fouad, H.; Hashem, M.; Niazy, A.A.; AlBadah, A. Titanium Oxide $\left(\mathrm{TiO}_{2}\right)$ /Polymethylmethacrylate (PMMA) Denture Base Nanocomposites: Mechanical, Viscoelastic and Antibacterial Behavior. Materials 2018, 11, 1096. [CrossRef] [PubMed]

35. Ali, I.L.; Yunus, N.; Abu-Hassan, M.I. Hardness, Flexural Strength, and Flexural Modulus Comparisons of Three Differently Cured Denture Base Systems. J. Prosthodont. Implant. Esthet. Reconstr. Dent. 2008, 17, 545-549. [CrossRef]

36. Farina, A.P.; Cecchin, D.; Soares, R.G.; Botelho, A.L.; Takahashi, J.M.F.K.; Mazzetto, M.O.; Mesquita, M.F. Evaluation of Vickers Hardness of Different Types of Acrylic Denture Base Resins with and without Glass Fibre Reinforcement. Gerodontology 2012, 29, e155-e160. [CrossRef] [PubMed]

37. Gad, M.M.; Al-Thobity, A.M.; Rahoma, A.; Abualsaud, R.; Al-Harbi, F.A.; Akhtar, S. Reinforcement of PMMA Denture Base Material with a Mixture of $\mathrm{ZrO}_{2}$ Nanoparticles and Glass Fibers. Int. J. Dent. 2019, 2019. [CrossRef] [PubMed]

38. ISO:1567 Dentistry—Denture Base Polymers; International Organization for Standardization: Geneva, Switzerland, 1999.

39. ISO:6507-1 Metallic Materials_-Vickers Hardness Test; International Organization for Standardization: Geneva, Switzerland, 2005; pp. 1944-1996.

40. Jiangkongkho, P.; Arksornnukit, M.; Takahashi, H. The Synthesis, Modification, and Application of Nanosilica in Polymethyl Methacrylate Denture Base. Dent. Mater. J. 2018, 2017-2142. [CrossRef]

41. Karacaer, O.; Polat, T.N.; Tezvergil, A.; Lassila, L.V.; Vallittu, P.K. The Effect of Length and Concentration of Glass Fibers on the Mechanical Properties of an Injection-and a Compression-Molded Denture Base Polymer. J. Prosthet. Dent. 2003, 90, 385-393. [CrossRef]

42. Abushowmi, T.H.; AlZaher, Z.A.; Almaskin, D.F.; Qaw, M.S.; Abualsaud, R.; Akhtar, S.; Al-Thobity, A.M.; Al-Harbi, F.A.; Gad, M.M.; Baba, N.Z. Comparative Effect of Glass Fiber and Nano-Filler Addition on Denture Repair Strength. J. Prosthodont. 2020, 29, 261-268. [CrossRef]

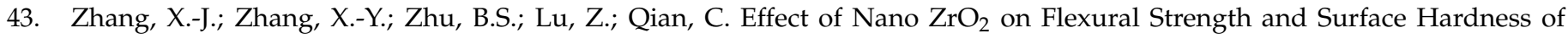
Polymethylmethacrylate. Shanghai J. Stomatol. 2011, 20, 358-363.

44. Naji, S.A.; Behroozibakhsh, M.; Kashi, T.S.J.; Eslami, H.; Masaeli, R.; Mahgoli, H.; Tahriri, M.; Ghavvami Lahiji, M.; Rakhshan, V. Effects of Incorporation of 2.5 and $5 \mathrm{Wt} \% \mathrm{Tio}_{2}$ Nanotubes on Fracture Toughness, Flexural Strength, and Microhardness of Denture Base Poly Methyl Methacrylate (PMMA). J. Adv. Prosthodont. 2018, 10, 113-121. [CrossRef] [PubMed]

45. Chen, S.-G.; Yang, J.; Jia, Y.-G.; Lu, B.; Ren, L. TiO 2 and PEEK Reinforced 3D Printing PMMA Composite Resin for Dental Denture Base Applications. Nanomaterials 2019, 9, 1049. [CrossRef] [PubMed]

46. Chen, R.; Han, Z.; Huang, Z.; Karki, J.; Wang, C.; Zhu, B.; Zhang, X.J. Antibacterial Activity, Cytotoxicity and Mechanical Behavior of Nano-Enhanced Denture Base Resin with Different Kinds of Inorganic Antibacterial Agents. Dent. Mater. J. 2017, 36, 693-699. [CrossRef] [PubMed] 